\title{
COMUNICAÇÃO VERBAL E NÃO VERBAL: FATORES QUE INFLUENCIAM AS RELAÇÕES ENTRE LÍDERES E LIDERADOS
}

\author{
https://dx.doi.org/10.48097/2674-8673.2021n5p02
}

\author{
Arandi Maciel Campelo ${ }^{1}$ \\ Carolina Queiroz da Silva ${ }^{2}$ \\ Débora Andrezza de Melo Lima ${ }^{3}$ \\ Natália Maria Correia e Sousa ${ }^{4}$ \\ Eronildo Ferreira do Carmo ${ }^{5}$
}

\section{RESUMO}

O presente estudo aborda a comunicação verbal e não verbal dentro do ambiente institucional. Foi construído através de pesquisa bibliográfica e coleta de dados com população composta por trabalhadores de trinta setores administrativos, somando noventa e três funcionários, realizada na Faculdade Metropolitana da Grande Recife no período de agosto a novembro de 2020. Apresenta como principal objetivo analisar a comunicação verbal e não verbal dentro do ambiente corporativo. Os referenciais teóricos apresentados para respaldos científicos foram, principalmente, Biderman (2009) e Cardoso (2006). De todo corpo amostral, apenas dezenove funcionários concordaram em participar da pesquisa. Para avaliação dos critérios analisados foi realizada a aplicação de um questionário de caráter qualitativo, através da plataforma Google forms. Os dados do questionário elucidaram possível receio por parte dos funcionários durante a realização da pesquisa, o que pode ter gerado divergências nas respostas, corroborando com o que foi abordado em todo o conteúdo, em que a ausência ou a má formulação da réplica de uma das partes da comunicação reduz a satisfação e a evolução dos processos dentro da empresa.

Palavras-chave: Comunicação empresarial. Cultura e clima organizacional. Linguagem Verbal. Linguagem corporal. Ruídos na comunicação .

Data de submissão: 28/01/2021

Data de aprovação: 22/02/2021

1 Orientador: Doutor em Educação - Universidade Federal de Pernambuco; Administrador - Universidade de Pernambuco - FCAP/UPE; Mestre em Planificación y Gestion Organizacional - UniversidadAutonoma de Madrid / Espanha; Mestre em Dirección y Organización de Hospitales y Servicios de Salud - Universidad Politécnica de Valencia / Espanha; Especialista em Marketing - FCAP/UPE; Consultor em Sistemas Organizacionais, desde 1984; Professor e Diretor Acadêmico da Faculdade Metropolitana da Grande Recife. E-mail: arandi.campelo@globo.com

2 Estudante do curso de Administração da Faculdade Metropolitana da Grande Recife.

E-mail: carolinaqueiroz539@gmail.com

3 Estudante do curso de Administração da Faculdade Metropolitana da Grande Recife.

E-mail: debyandrezza@hotmail.com/dandrezza185@gmail.com

4 Estudante do curso de Administração da Faculdade Metropolitana da Grande Recife.

E-mail: natislamer@gmail.com

${ }^{5}$ Coorientador. Professor da Faculdade Metropolitana da Grande Recife.

E-mail: proferon100@gmail.com 


\begin{abstract}
The present study addresses verbal and non-verbal communication within the institutional environment. It was built through bibliographic research and data collection with a population composed of workers from thirty administrative sectors, totaling ninety-three employees, held at the Metropolitan Faculty of Greater Recife from August to November 2020. Its main objective is to analyze verbal communication and non-verbal within the corporate environment. The theoretical references presented for scientific support were, mainly, Biderman (2009) and Cardoso (2006). Of the entire sample body, only nineteen employees agreed to participate in the survey. To evaluate the analyzed criteria, a qualitative questionnaire was applied, using the Googleforms platform. The questionnaire data elucidated possible fear on the part of the employees during the conduct of the research, which may have generated divergences in the answers, corroborating with what was addressed in all the content, in which the absence or the poor formulation of the reply of one of the communication parts reduce satisfaction and evolution of processes within the company.
\end{abstract}

Keywords: Business communication. Culture and organizational climate. Verbal language. Body language. Communication noise.

\title{
INTRODUÇÃO
}

Este artigo aborda o tema da comunicação verbal e não verbal e os fatores que influenciam as relações entre líderes e liderados, focando no estudo de caso do setor administrativo da Faculdade Metropolitana da Grande Recife. O artigo está estruturado com os tipos de comunicação dentro das organizações, além das influências da cultura no clima organizacional e comunicação interpessoal nas organizações, abordando os subitens comunicação verbal, comunicação não verbal e linguagem corporal como ferramenta de trabalho.

O tema escolhido importa como uma ferramenta básica para o desenvolvimento coletivo e individual no meio laboral sobre como se portar ou como transmitir a correta mensagem daquilo que se quer dizer para que a comunicação seja efetuada de maneira clara, objetiva e sem ruídos. Contemplando o campo investigativo, o instrumento utilizado na pesquisa foi um questionário semiaberto.

$\mathrm{Na}$ pesquisa constam indagações sobre como a liderança lida com este assunto e sobre como os liderados e colaboradores sentem-se ao serem abordados de maneira positiva ou negativa no seu cotidiano. São fornecidas informações sobre a forma de desempenho que a equipe tem e os tipos de estímulos que poderão receber para que venham a desenvolver suas atividades com maior eficiência. 


\section{REFERENCIAL TEÓRICO}

Há uma grande necessidade hoje, no mundo empresarial, de que um colaborador tenha, junto as suas qualidades profissionais, o poder de ser um bom comunicador e de transmitir informações corretamente durante entrevistas de emprego, conversas formais, reuniões de negócios e, até mesmo, durante conversas informais. Com isso, o referencial trata da maneira eficaz a necessidade de entender e ser entendido na comunicação entre líderes e liderados.

\section{A comunicação dentro das organizações}

Dada a importância da comunicação nos demais ambientes de trabalho, é crucial que se perscrute sua utilização e efeitos nas corporações. Portanto, sabendo dos recursos exigidos para uma comunicação eficaz e dinâmica, assim como seu impacto para a aprendizagem e transmissão de informações na empresa, foram discorridos os assuntos demandados.

Desta forma, a linguagem verbal e não verbal e, também, as relações interpessoais e culturais foram alguns dos tópicos que serviram de base para o desenvolvimento da pesquisa de campo.

\section{Comunicação Verbal}

Na visão de Cruz (2016), mestra em liderança, o processo da comunicação diante das organizações é essencial para demonstrar conhecimento, entendimento e avaliações de uma maneira concreta e objetiva.

Assim, "a comunicação é essencial para todos, pois é através dela que o conhecimento pode ser adquirido e repassado. Podemos ter o livre acesso à expressão, oportunidade de amadurecer, de aprender, ensinar, desenvolver [...]” (CRUZ, 2016, p. 1)

O fundamento das divergências dentro da cultura organizacional se refere aos erros de comunicação, sendo observada através do emissor e receptor.

a) Emissor: indivíduo que transmite a mensagem.

b) Receptor: instrumento com finalidade de decodificar a mensagem ou o indivíduo que recebe a mensagem.

c) Linguagem: uso da escrita ou da fala como meio de comunicação.

d) Mensagem: junção de informações que podem ser divulgadas.

Uma comunicação eficiente nas instituições constitui uma ligação de todos estes sentidos, sendo desejada que aconteça efetivamente de forma eficaz. Saber se comunicar de uma maneira específica é necessário para expandir processos, atingir metas e desenvolver 
maior produtividade. A prática acaba sendo essencial para o aprimoramento das habilidades comunicativas, tais como a obtenção de uma oratória adequada.

Conforme cita Cardoso (2006):

Cada vez mais, tornam-se claro como os processos de comunicação contribuem para desenvolver formas de inter-relação mais participativas e, portanto, mais comprometidas, dando maior flexibilidade às organizações como base de sua permanente transformação e facilitando sua interação social de modo responsável para conjugar seus interesses com as condições culturais, econômicas e políticas nas quais se movem. (CARDOSO, 2006, p. 1132).

A comunicação formal utilizada dentro das organizações visa manter aquilo que é mais vantajoso para ela própria, deixando claro quais são os canais internos e externos que ela pretende usar e qual mensagem deve ser enviada e recebida pelos canais, pontualmente definida pela instituição, de acordo com o planejamento da empresa. A comunicação informal são relações sociais que acontecem livremente entre as pessoas e a empresa de maneira independente da formal.

Para Marinho (2004), a comunicação informal desenvolve melhor a ligação entre os funcionários, evoluindo na execução do trabalho e também constituindo convívio social aos profissionais. Com isso, motiva os trabalhadores a buscar resultados e trazer feedback positivo com o intuito de contribuir com a empresa, destacando o "gatekeeper tecnológico",6.

\section{Comunicação não verbal}

Este tipo de comunicação dá-se pelo uso de vários modelos de expressões, expressões que são chamadas muitas vezes de linguagem corporal, e delas se recebem informações através de comportamentos que devem ser claramente entendidos tanto por quem emite a informação quanto por quem recebe a informação. Segundo Coachingsb (2018):

\footnotetext{
A linguagem corporal está relacionada à comunicação não verbal. Ela aparece na nossa postura, nos gestos, no quão próximo estamos de outra pessoa ao conversar com ela, nas expressões faciais e até no movimento que nossos olhos fazem. É através da linguagem corporal, muitas vezes, que podemos identificar o real significado de uma mensagem ou transmiti-la da maneira que não gostaríamos. (COACHINGSB, 2018, p. 1).
}

Conforme Biderman (2009), as palavras representam em média apenas 7\% do processo de comunicação, o tom de voz $38 \%$, e os sinais não verbais $55 \%$. Olhando para esses dados

6 Gatekeeper tecnológico: conceito mais utilizado na literatura para determinar aqueles que, na empresa, controlam o fluxo de informação entre os membros da organização e fazem circular as mensagens, entrando em contato com outros grupos. 
percebe-se o quão é importante agir bem diante do olhar de quem nos observa e percebemos também que nosso comportamento é tão importante quanto nossas palavras.

E é pensando na importância da comunicação não verbal que muitas organizações adotam modelos de gestão que facilitam o entendimento, dando uma clareza visual de como, quando e onde o processo se desenvolve, usando cores, formas e elementos gráficos como fluxogramas.

Como cita Petenate (2018), os processos de melhoria contínua, controle e planejamento necessitam da gestão visual, apresentando diferentes tipos de aplicações que se enquadram em diferentes situações para a compreensão da situação atual, sendo sistemas que não precisam de muitos recursos, porém são práticos e de fácil entendimento.

\section{Linguagem corporal como ferramenta de trabalho}

Existem situações em que somos induzidos mais pelo que vemos e sentimos do que pelo que ouvimos. Por isso a influência que as mensagens não verbais exercem sobre alguém tem muito mais peso do que apenas o que essa pessoa diz. Tratando-se de linguagem corporal é possível perceber traços de diferentes tipos de personalidades, o que nos leva a descrever um pouco sobre a ligação que existe entre a liderança e a linguagem corporal dentro do trabalho.

Na opinião de Rector e Trinta (2003, p. 5), “o corpo humano pode servir à comunicação interindividual. Quando isto ocorre somos o emissor, que transmite para o outro, o receptor, uma mensagem, consciente ou inconsciente, controladamente ou não." Por isso um líder deve estar atento na mensagem que ele passa para seus liderados, tendo em mente que os resultados das mensagens que são enviadas de forma correta apresentam bons retornos e a utilização do nosso corpo em nosso favor certamente acarretarão em ganhos. Exemplificando um gesto simples como a cabeça erguida, que nos mostra mais confiantes e confortáveis com o que há a nossa volta. Por outro lado existem movimentos e sinais que se devem evitar como cabeça baixa, corpo encolhido e olhar para baixo, pois eles demonstram fraqueza e fragilidade. Sobre esta temática Camargo (2018) afirma que:

\footnotetext{
o objetivo é mostrar e ensinar de modo direto e simples como a linguagem corporal pode ampliar a nossa capacidade de liderança. Pequenos gestos, posturas, movimentos de mãos e de cabeça são capazes de potencializar a liderança de qualquer pessoa. (CAMARGO, 2018, p. 12).
}

Como líderes, muitas vezes, cabe a nós recrutar e selecionar pessoas ou até mesmo outros líderes, então temos que perceber que é possível reconhecer um líder nato por sua 
linguagem corporal, mas também é possível treinar pessoas para que elas saibam utilizar os sinais corretos que favorecem a impressão que é necessária passar para assumir este posto.

Conforme Camargo (2018):

Aqui adentramos um campo interessante: se você trabalha com recrutamento e seleção de pessoal, essas informações simples podem ajudá-lo a avaliar se determinados indivíduos são adequados para cargos de liderança. Antes mesmo da dinâmica de grupo, a postura dos candidatos, sua movimentação corporal, a posição do queixo e das mãos, a maneira como carregam seus pertences, o timbre e o volume da voz dão ao recrutador pistas importantes sobre cada um dos postulantes. (CAMARGO, 2018, p. 14).

\section{As influências da cultura no clima o rganizacional}

A cultura organizacional é um conjunto de hábitos e crenças estabelecidos por normas, valores, atitudes e expectativas compartilhadas por todos os membros da organização, mudando constantemente de acordo com a necessidade de mudança e desenvolvimento interno de um grupo, o que repercute diretamente no clima organizacional, sendo este, representado pelo ambiente psicológico e social da organização, resultando em emoções e graus de satisfação, gerando desejos e expectativas que tendem a aumentar ou diminuir o entusiasmo e a produtividade dos colaboradores. (LÓPEZ, 2016; SILVA et al, 2020; SOUZA et al, 2020).

Nesse sentido, "os estudos culturais permitiram a compreensão da organização como um sistema de signific ado compartilhado, capaz de aprender, mudar e evoluir ao longo do tempo, por meio da interação entre seus membros e entre si mesma e o seu ambiente." (GUIMARÃES; SQUIRRA, 2007, p. 51).

A cultura é a identidade de uma empresa e ao ser empregado no dia a dia do ambiente empresarial torna-se um importante meio de comunicação, gerando trocas de pensamentos e opiniões, trazendo a capacidade de lidar com antecipação e tranquilidade diante das mudanças. Como diz Marchiori (2006):

A cultura e a comunicação organizacional vêm chamando a atenção dos profissionais uma vez que está se tornando um tema fundamental e inquestionável nas empresas. Isso porque atuam nas raízes de uma organização e posicionam a área de comunicação de uma forma estratégica. (MARCHIORI, 2006, p. 26).

Nesse segmento, tornou-se fundamental a função de relações públicas, pois é vista como a principal ferramenta de gerenciamento e de grande importância nas organizações, a qual está diretamente ligada ao relacionamento entre a empresa e seus stakeholders ${ }^{7}$. (MARCHIORI, 2006).

7 Stakeholders: público estratégico que descreve uma pessoa ou grupo que tem interesse em uma empresa, negócio ou indústria, podendo ou não ter feito um investimento neles. 
A Comunicação é um meio de grande importância e é fundamental para que as organizações se comuniquem e interajam diariamente, com o intuito de estabelecer uma boa relação, ambiente agradável e alinhamento de ideias entre as equipes e setores. É necessário que a comunicação seja transmitida da melhor forma possível, sendo de forma clara e objetiva para o melhor entendimento de todos.

Quando em uma organização a comunicação flui de maneira eficaz o clima organizacional torna-se mais leve, as pessoas tendem a se comunicar melhor e consequentemente ocorre um avanço de produtividade dos funcionários, os feedbacks são positivos e por consequência, acabam influenciando de forma direta na motivação, satisfação e criatividade dos colaboradores.

Da mesma forma, quando numa determinada organização a comunicação não ocorre da maneira correta, são causados ruídos que afetam o clima organizacional e, por consequência, o ambiente torna-se pesado, gerando desconforto, desinteresse nas obrigações e conflitos interpessoais. “[...] Pode-se dizer que o clima é bom quando há um nível baixo de rotatividade funcional, com isso um alto tempo de permanência dos colaboradores na organização, também quando eles sentem orgulho em participar da empresa.” (OLIVEIRA, et al, 2014, p. 56).

Cabe ao líder, por meio de diálogos, influenciar e ser o exemplo a ser seguido, conquistando sua equipe com o intuito de manter uma boa relação. Confiança é importante neste processo, pois com a ausência dela torna-se difícil a convivência e o relacionamento entre seus líderes e liderados. O bom líder consegue facilmente a confiança de sua equipe, sabe ser motivador e trabalhar o potencial das pessoas. Conforme descreve Oliveira (2014):

\begin{abstract}
A boa comunicação é essencial para a eficácia de qualquer organização ou grupo. Pesquisas indicam que as falhas de comunicação são as fontes mais frequentemente citadas de conflitos interpessoais. Uma das principais forças que podem impedir o bom desempenho de um grupo é a falta de comunicação eficaz. A comunicação precisa ser transparente e compreensível. (OLIVEIRA et al, 2014, p. 31).
\end{abstract}

\title{
Comunicação interpessoal nas organizações
}

Conforme supracitado, a comunicação é essencial para demonstrar progressos. Em meio à comunicação interpessoal nas organizações, o crescimento profissional é auxiliado, trazendo vantagem em relação à carreira do empregado e, também, ao avanço da corporação. Assim, é fundamental que os empregados melhorem sua comunicação interpessoal no ambiente de trabalho, repassando informações cujas contribuições irão direcionar a organização no meio da conjunção de uma equipe profissional. A esse respeito Adler \& Towne (2002) dizem que: 
o número de pessoas envolvidas. Quando a qualidade da interação é o critério, o oposto da comunicação impessoal é a interação pessoal, e não a comunicação de grupo, pública ou de massa. (ADLER; TOWNE, 2002, p. 10).

A oralidade influencia as pessoas ao se comunicarem regularmente, com o intuito de produzir e planejar discursos, colaborando com o ambiente organizacional da empresa. Possibilita que as sugestões concebidas pelos membros da empresa tornem-se informações assertivas, em lugar de transmitir entraves ou bloqueios que interfiram na acessibilidade e estabelecimento da comunicação. Portanto, dada tal importância, a oralidade remete aos conceitos relativos à associação e comunicação interpessoal, desenvolvendo troca de informações e cooperação coletiva mediante as resoluções necessárias às organizações.

Assim, conforme expressa Moreira (2012):

\begin{abstract}
Passa-se a exigir algo a mais desse super profissional: a competência humana. Habilidades de relacionamento interpessoal tornam-se um diferencial que as empresas buscam em seus colaboradores. Exemplo disso é o comportamento assertivo, uma habilidade cada vez mais valorizada, pois gera, nas organizações, um ambiente em que a comunicação flui de maneira clara e dinâmica. Os problemas são vistos como parte do cotidiano, enfrentados com maturidade e efetivamente resolvidos. (MOREIRA, 2012, p. 113).
\end{abstract}

\title{
METODOLOGIA
}

O objeto geral de estudo deste artigo é a comunicação verbal e não verbal, permitindo, desta forma, verificar o grau de importância que existe na presença e na ausência da mesma no ambiente corporativo. Como objetivos específicos visam-se:

a) Identificar como lideres desenvolvem técnicas mais eficientes no sentido de elaborar um planejamento que facilite o diálogo entre líderes e liderados;

b) Fundamentar a acessibilidade da interpretação na comunicação dentro da equipe de trabalho;

c) Propor estratégias eficazes para um melhor empenho da equipe, intensificando os relacionamentos laborais e proporcionando um melhor clima ao ambiente organizacional.

A escolha do método bibliográfico e da pesquisa de campo teve a finalidade aplicada, com análise propositiva e abordagem centrada nos aspectos qualitativos. Quanto ao instrumento da pesquisa foi elaborado um questionário de caráter semiaberto. 


\section{DESENVOLVIMENTO DA PESQUISA DE CAMPO}

Esta pesquisa de campo foi realizada na Faculdade Metropolitana da Grande Recife ${ }^{8}$, localizada na cidade de Jaboatão dos Guararapes, estado de Pernambuco.

O universo investigado foi o setor administrativo da faculdade, perfazendo um total de noventa e três funcionários. A amostra contou com a participação de dezenove pessoas.

A comunicação com seus superiores é de fácil acesso?

19 respostas

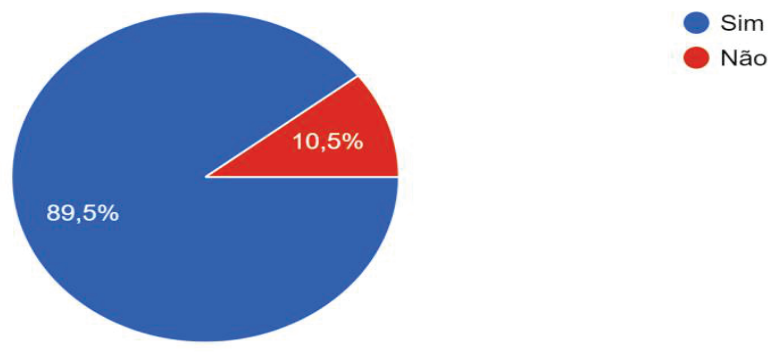

A maioria dos inquiridos apontou que tem uma comunicação de fácil acesso com os superiores. Apenas 10,5\% disseram que não.

Como você se sente em relação à comunicação interna da empresa?

19 respostas

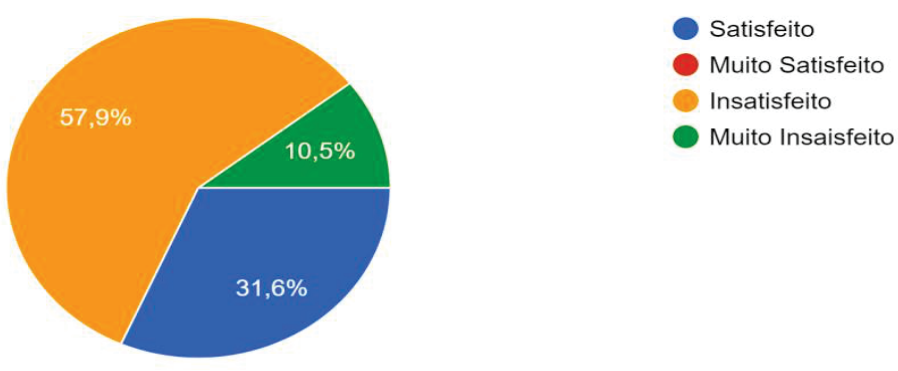

Apesar da maioria das respostas terem sido "sim" na questão anterior, o grau de insatisfação é maior que o de satisfação, conforme 57,9\% dos entrevistados.

8 Faculdade Metropolitana da Grande Recife. Instituição particular, localizada em Jaboatão dos Guararapes, Pernambuco, fundada em 2001, mantida pela União das Escolas Superiores de Jaboatão (UNESJ). 
Você possui uma relação de fácil comunicação com sua equipe de trabalho?

19 respostas

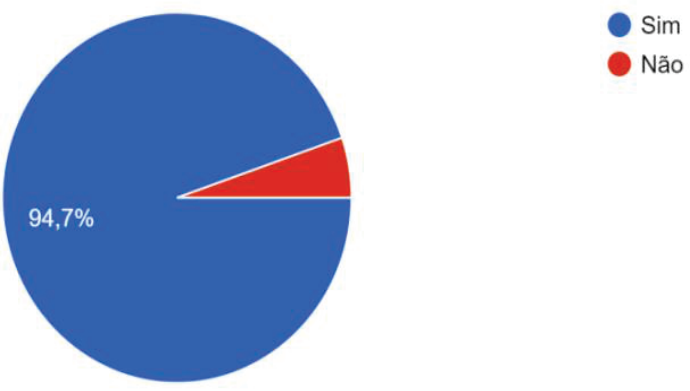

97,7\% dos inquiridos revelaram que eles têm uma relação de fácil comunicação com sua equipe.

Quais os meios de comunicação são utilizados na sua empresa?

19 respostas

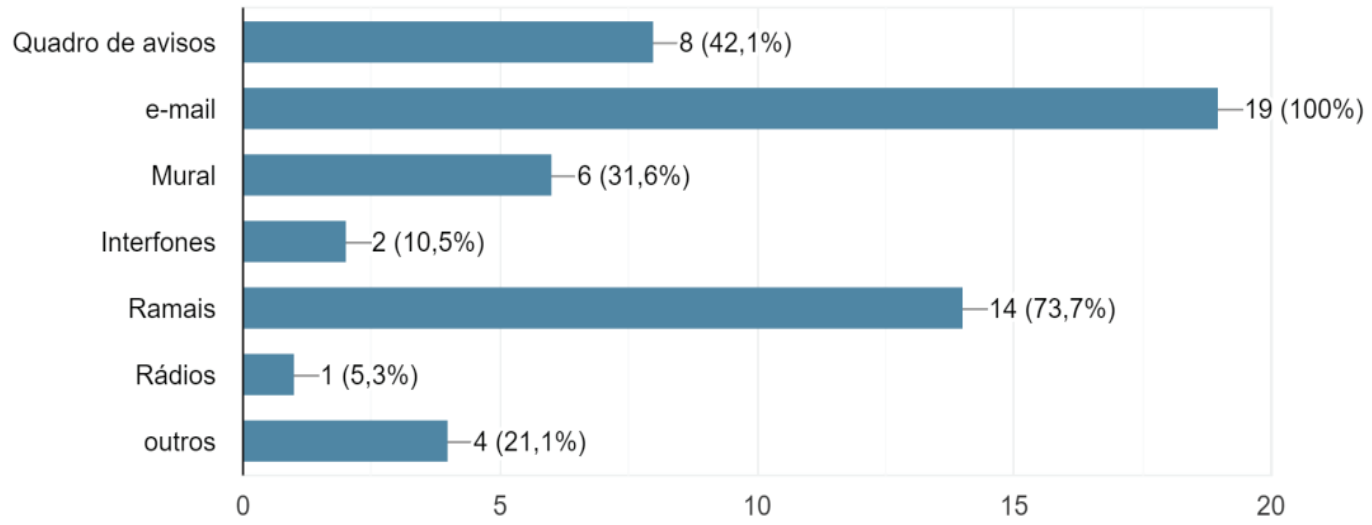

Apesar de afirmar que são usados vários meios de comunicação, os inquiridos confirmaram que o e-mail é o meio de comunicação mais usado na instituição como total de $100 \%$, seguido pelos ramais com o total de $73 \%$.

Descreva abaixo qual ou quais meios de comunicação são usados frequentemente para interação com a liderança: 19 respostas

"E-mails, WhatsApp e comunicação pessoal"

"Reuniões"

"Pessoalmente, por WhatsApp ou e-mail" 
Dentre todas as respostas merecem destaque as respostas acima, pois elas revelam a interação das relações de forma pessoal com a liderança.

\section{Descreva abaixo qual ou quais meios de comunicação são usados frequentemente para interação com a equipe de trabalho: 19 respostas \\ "Reuniões, saídas em grupo, brainstorming."}

Com base neste questionamento merece destaque a resposta acima, que revelou uma técnica usada em grupo, "brainstorming", contribuindo para a ideia de Marinho (2004), que diz que a comunicação informal desenvolve melhor a ligação entre os funcionários, evoluindo na execução do trabalho e também constituindo convívio social aos profissionais.

\section{A instituição ouve seus colaboradores e dá retorno?}

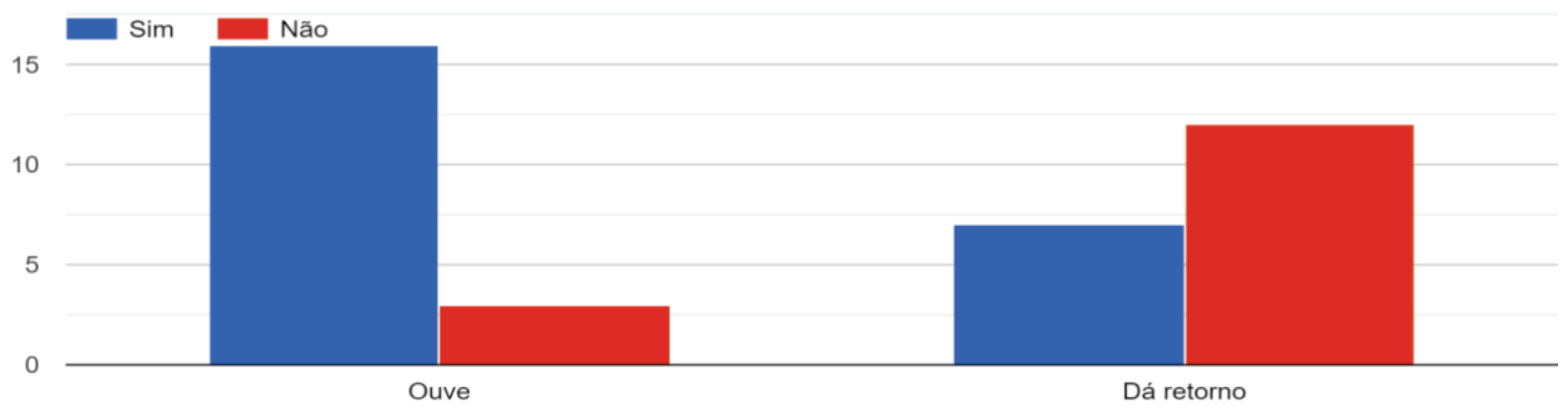

A maioria dos entrevistados revelou que a instituição ouve os seus colaboradores, mas em contrapartida a maioria revelou que não dá retorno, deixando clara a disparidade que existe entre ouvir e dar retorno.

9 Brainstorming: técnica definida pela apresentação espontânea de pensamentos e ideias, tendo como propósito solucionar alguma questão, problema, ou produzir algo criativo. 
Assinale abaixo numa escala de 0 a 10 o seu nivel de satisfação em relação à comunicação ao ambiente de trabalho?

19 respostas
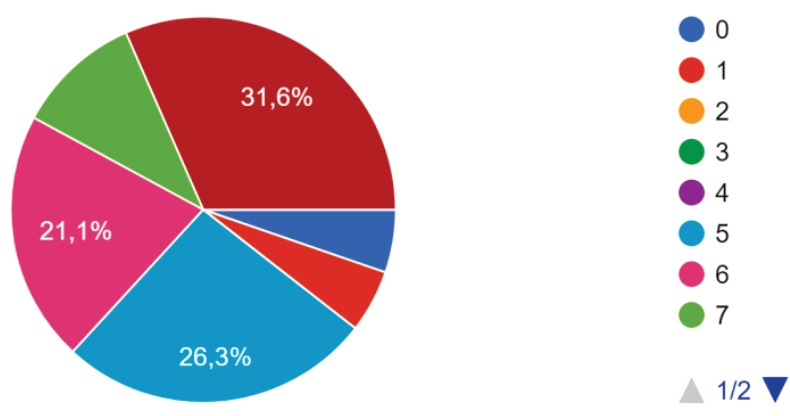

Numa escala crescente de zero a dez a maioria dos inquiridos selecionaram diferentes níveis de satisfação em relação à comunicação, somando 31,6\% para o nível 1, 26,3\% para o nível 5, e 21,1\% para o nível 6 de satisfação.

Com que frequência seu lider o ouve e presta atenção no que fala?

19 respostas

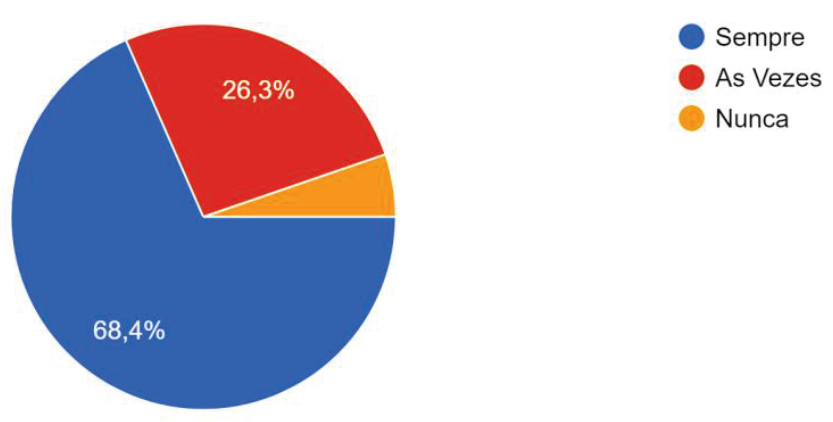

Com $68,4 \%$ a maioria dos inquiridos revelou que sempre a liderança presta atenção no que eles falam.

Com que frequência acontecem reuniões internas no seu setor de trabalho: 19 respostas

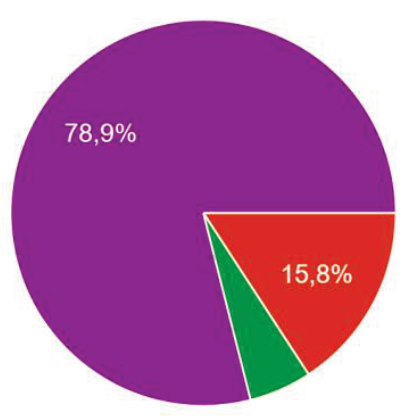

Diária

Semanal

Quinzenal

Mensal

As reuniões tem datas esporádicas 
Segundo os entrevistados o tipo de reunião que mais acontece são as esporádicas.

\section{CONSIDERAÇÕES FINAIS}

Este artigo foi desenvolvido através de pesquisa na Faculdade Metropolitana da Grande Recife, em Jaboatão dos Guararapes. O objeto de estudo foi verificar a importância da comunicação verbal e não verbal efetiva no ambiente de trabalho. $\mathrm{O}$ objetivo geral desse artigo foi atingido, visto que houve a análise, dentro do ambiente laboral, da comunicação verbal e não verbal utilizadas. Entre os objetivos específicos não houve diferentes resultados, de maneira que a pesquisa efetuada possibilitou a compreensão de como líderes dialogam com liderados e como acontece o diálogo entre os integrantes da empresa. Assim, foi permitido o mapeamento e proposição de estratégias para aprimorar a dinamicidade da comunicação laboral. A pesquisa consistiu no uso do método bibliográfico e pesquisa de campo, com abordagem de aspecto qualitativo. Diante do exposto pode-se elucidar que, embora a comunicação ocorra entre os setores, existem fatores que mostram algumas divergências nas respostas da presente pesquisa, relacionados ao feedback e à satisfação dos colaboradores no ambiente corporativo, tendo em vista que há o recebimento da mensagem e ao mesmo tempo existe insatisfação sobre a réplica da mesma, o que corrobora com a presente pesquisa, levando em consideração que a ausência ou a má formulação da réplica de uma das partes da comunicação reduz a satisfação e a evolução dos processos dentro da empresa. Recomenda-se a busca pelo investimento na divulgação da comunicação interna, visando promover treinamentos e programas de interação entre líderes e liderados para que haja uma melhor conexão entre os mesmos e assim seja eliminado o receio que existe ao expor sugestões, críticas e elogios que foram perceptíveis durante a pesquisa.

\section{REFERÊNCIAS}

ADLER, Ronald B.; TOWNE, Neil. Comunicação interpessoal. 9. ed. Rio de Janeiro: LTC, 1999.

BIDERMAN, Albert. Nonverbal Communication. 3. ed. Piscataway, New Jersey: Aldine Transaction, 2009.

CAMARGO, Paulo Sérgio de. Liderança e linguagem corporal: técnicas para identificar e aperfeiçoar líderes. São Paulo: Summus Editorial, 2018.

CARDOSO, Onésimo de Oliveira. Comunicação empresarial versus comunicação organizacional: novos desafios teóricos. 2006. Rev. Adm. Pública. Vol. 40, n.6, pp.1123- 
1144. ISSN 1982-3134. https://doi.org/10.1590/S0034-76122006000600010. Disponível em: https:/www.scielo.br/scielo.php?pid=S003476122006000600010\&script=sci_abstract\&tlng= pt. Acesso em: 1 abr. 2020.

CRUZ, O Papel Estratégico da Comunicação nas Organizações. 2016. Disponível em: https://administradores.com.br/artigos/o-papel-estrategico-da-comunicacao-nas-organizacoes Acesso em: 1 abr. 2020.

DICIO. Dicionário online de português. Brainstorming. Dicio. 2009. Disponível em: https://www.dicio.com.br/brainstorming/. Acesso em: 26 nov. 2020.

LÓPEZ, L.; MARCELA, L. Cultura organizacional: entre el individualismo y el colectivismo. Colombia: Editorial Sello Editorial, Universidad del Tolima, 2016.

GUIMARÃES, A. S.; SQUIRRA, S. C. de M. Comunicação organizacional e o processo comunicacional: uma perspectiva dialógica. Revista FAMECOS. 2007, n ${ }^{\circ} 33$. Disponível em: https://revistaseletronicas.pucrs.br/ojs/index.php/revistafamecos/article/view/3433/2695

Acesso em: 02 abr. 2020.

MARCHIORI, Marlene. Cultura e Comunicação Organizacional: um olhar estratégico sobre a organização. 2. ed. São Caetano, São Paulo: Difusão, 2006.

MARINHO, Sandra. Comunicação Informal nas Organizações: um estudo de caso em I\&D. Portugal, 2004. Disponível em: https://repositorium.sdum.uminho.pt/bitstream/1822/2728/1/smarinho_VIIALAIC_2004.pdf Acesso em: 02 abr. 2020.

MOREIRA, Elen Gongora. Clima organizacional. Curitiba: IESDE Brasil S.A, 2012.

OLIVEIRA, Elisete et al. Cultura Organizacional. Londrina: Educacional S.A, 2014.

PETENATE, Marcelo. Gestão Visual. Escola EDTI. 25 de Mar. 2018. Disponível em: https://www.escolaedti.com.br/gestao-visual. Acesso em: 03 abr. 2020.

RECTOR, M.; RAMOS TRINTA, A. Comunicação do corpo. São Paulo: Ática, 2003.

SBCOACHING. Linguagem corporal: o que é, diferentes tipos e importância. 2018. Disponível em: https://www.sbcoaching.com.br/blog/linguagem-corporal/. Acesso em: 03 abr. 2020.

SOUZA, I. M.; BACHTOLD, C. A. Cultura organizacional e sua influência no desempenho e motivação no trabalho do servidor público: estudo de caso na prefeitura de Colombo-PR. Revista Mundi Engenharia, Tecnologia e Gestão. v.5, n.4, 2020.

SILVA SOBRINHO, P .; MONTEIRO, M. S. Administração Participativa e sua Influência no Clima Organizacional: Uma Pesquisa Bibliográfica. Revista de ciências sociais aplicada. v.1, n.1, 2020. 


\section{APÊNDICE A - Modelo do questionário da pesquisa de campo}

Este questionário tem por finalidade analisar a comunicação verbal e não verbal dentro do ambiente corporativo.

1) A comunicação com seus superiores é de fácil acesso?
( )SIM
( ) NÃO

2) Como você se sente em relação à comunicação interna da empresa?
( )SATISFEITO
( )MUITO SATISFEITO
( )INSATISFEITO
( )MUITO INSATISFEITO

3) Você possui uma relação de fácil comunicação com sua equipe de trabalho?
( )SIM
( ) NÃO

4) Quais os meios de comunicação são utilizados na sua empresa?
a) ( )Quadro de avisos
b) ( )e-mail
c) ( ) mural
d) ( )interfones
e) ( )ramais
f) ( )rádios
h) Outros:

5) Descreva abaixo qual ou quais meios de comunicação são usados frequentemente para interação com a liderança:

6) Descreva abaixo qual ou quais meios de comunicação são usados frequentemente para interação com a equipe de trabalho:

7) A instituição ouve seus colaboradores e dá retorno?

$\begin{array}{lcc} & \text { Sim } & \text { Não } \\ \text { OUVE } & (\text { ) } & (\text { ) } \\ \text { DÁ RETORNO } & (\text { ) } & (\text { ) }\end{array}$

8) Assinale abaixo numa escala de 0 a 10 o seu nível de satisfação em relação à comunicação ao ambiente de trabalho?

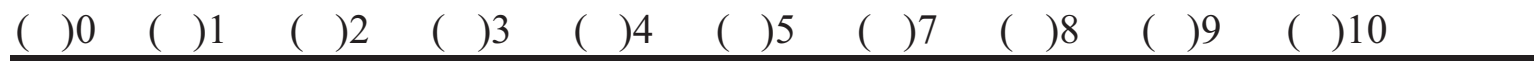

9) Com que frequência seu líder o ouve e presta atenção no que fala?
( ) Sempre
( ) Às vezes
( ) Nunca 
10) Com que frequência acontecem reuniões internas no seu setor de trabalho?
( ) Diária - ( ) Semanal - ( ) Quinzenal - ( )Mensal
( ) As reuniões têm datas esporádicas. 